\title{
A pesca em comunidades ribeirinhas na região do médio rio Madeira, Rondônial
}

\section{Fishery in riverine communities of the middle Madeira river Rondônia}

Carolina Rodrigues da Costa Doria - Professora na Universidade Federal de Rondônia/ UNIR, Departamento de Biologia/ Laboratório de Ictiologia e Pesca. Doutora pelo Núcleo de Altos Estudos Amazônicos, UFPA. E-mail: carolinarcdoria@uol.com.br; carolinarcdoria@unir.br

Luiz Fontes Machado Neto - Biólogo. Universidade Federal de Rondônia/UNIR, Laboratório de Ictiologia. E-mail: luizmachadousu@hotmail.com

Suelen Taciane Brasil de Souza - Mestranda do Programa de Pós-graduação em Desenvolvimento Regional e Meio Ambiente. E-mail: suelenbrasil.pesca@gmail.com

Maria Alice Leite Lima - Doutoranda do Programa de Pós-graduação em Desenvolvimento Regional e Meio Ambiente, Universidade Federal de Rondônia/UNIR, Laboratório de Ictiologia e Pesca. E-mail: alicelima.lima@gmail.com

\section{Resumo}

A importância da pesca na unidade familiar de produção (UFP) e a delimitação dos fatores que a influenciam constituem o hiato na caracterização da atividade em regiões da Amazônia sob iminência de impactos de grandes projetos. Este estudo avaliou a dinâmica e a importância da pesca em UFP de comunidades ribeirinhas à jusante da cachoeira do Teotônio (rio Madeira) e a influência na composição e abundância das espécies capturadas, de fatores ambientais, distância dos mercados e destinação da captura. Entre agosto/2009 e julho/2010 (período pré reservatório), 23 famílias registraram informações diárias da atividade que permitiram analisar a captura total e específica de pescado consumido e comercializado e o esforço de pesca. Os resultados demostraram a importância da pesca familiar (produção média: $2.403 \pm 2.261 \mathrm{~kg}$. família ${ }^{-1} \cdot$ ano $^{-1}$; e do consumo médio per capita: 440 g.dia ${ }^{-1}$ ) e padrões entre as comunidades que refetem ambos os fatores ambientais, distância do pescado consumidor e destino da captura.

\section{Palavras-chave}

Recursos Pesqueiros. Consumo do Pescado. Composição Específica. Amazônia.

\begin{abstract}
The fisheries importance in the family unit of production and the identification of factors that influence it, make up the gap in the characterization of the activity in the Amazon region under the impendence of large projects impacts. This study evaluated and compared the dynamics and the importance of fishing in the family unit in riverside communities downstream of Santo Antonio Dam (Madeira River) and, the influence of environmental, isolation and fishing destination in the composition and abundance of the catch. Between August/2009 and July/2010 (pre-dam period), 23 families recorded daily information about the activity to analyze the total catch, monthly and specific fish consumed and marketed and fishing effort. The results show the importance of family fishing (average production: $2.403 \pm 2.261 \mathrm{~kg}$.family.year ${ }^{-1}$; consumption per capita: 440 g.day ${ }^{-1}$ ) and that differences between communities are related to both destination, isolation and environmental factors.
\end{abstract}

\section{Keywords}

Fishery Resources. Fish Consumption and Species Composition. Amazon. 


\section{INTRODUÇÃO}

A atividade pesqueira na Amazônia sempre foi destaque no contexto econômico e social, tornando-se uma das principais atividades extrativistas da região (SMITH, 1979; SANTOS et al., 1991; SANTOS; FERREIRA, 1999). Além do mais, envolve o maior contingente populacional de trabalhadores (FABRÉ; ALONSO, 1998), estimados em 368.000 pescadores que exercem a pesca artesanal de pequena escala (MPA 2010).

A importância e a dinâmica da atividade na Amazônia são demonstradas em vários trabalhos (SMITH, 1979; ISAAC; BARTHEM, 1995; ISAAC; RUFFINO, 2000; GONÇALVES; BATISTA, 2008) e alguns destacaram a bacia do rio Madeira (GOULDING, 1979; SANTOS, 1986/1987; CARDOSO; FREITAS, 2007; DORIA et al., 2012). Entretanto, estes estudos avaliaram principalmente os desembarques realizados nos grandes mercados pesqueiros do eixo principal nos rios Solimões/Amazonas, limitando o entendimento da pesca nos tributários do rio Amazonas (CARDOSO; FREITAS, 2012; INOMATA; FREITAS, 2015) e em suas comunidades ribeirinhas ${ }^{1}$ onde a atividade é realizada (LIMA; DORIA; FREITAS, 2012).

As práticas produtivas e os hábitos dessas comunidades possuem grande relação com a natureza e seus ciclos naturais (RÊEG, 1999). Especialmente a pesca, que em ambientes amazônicos é diretamente influenciada pelo ciclo hidrológico regional (JUNK 1989; BATISTA; ISAAC, VIANA, 2004). A dinâmica da atividade pesqueira desenvolvida na Amazônia apresenta diferenças não somente em função das características ambientais, mas também em função das características dos atores, das espécies exploradas, dos apetrechos e das embarcações utilizados, do destino final da produção, bem como da demanda e da proximidade do mercado consumidor (ISAAC; RUFFINO: MELO, 2000; SANTOS; SANTOS, 2005; CARDOSO; FREITAS, 2007; ISAAC; ALMEIDA, 2011, ISAAC et al., 2015). Estas características também afetam o padrão alimentar e o consumo do pescado das comunidades ribeirinhas e urbanas. As escolhas alimentares podem variar de acordo com: acesso a diferentes itens alimentares, a sazonalidade do recurso, bem como as condições socioeconômicas e/ou culturais (SILVIA; BEGOSSI, 2009; ISAAC et al., 2015).

$\mathrm{Na}$ Amazônia, o consumo do pescado é mais intenso em áreas isoladas dos grandes centros porque estão sujeitas a altos custos de transporte para o uso

Reconhecidas como comunidades tradicionais no Decreto Presidencial no 6.040 (BRASIL, 2007), as comunidades ribeirinhas têm a pesca artesanal como principal atividade econômica, além disso, podem desenvolver outras atividades extrativistas e de subsistência na unidade de produção familiar (NEVES, 2005). 
de bens e serviços das áreas urbanas (ISAAC et al., 2015). Nas comunidades mais próximas dos centros urbanos o consumo do pescado diminui em proporção com os demais tipos de proteína animal, devido a facilidade de acesso a outros produtos nos mercados locais, provocando também menor dependência dos recursos naturais (MURRIETA et al., 2008; COSTA et al., 2013).

Entender como essas diferenças afetam a dinâmica da pesca e o consumo do pescado nas comunidades, pode oferecer informações sobre abundância e diversidade dos recursos naturais disponíveis no ambiente, bem como gerar indicadores de conservação (ISAAC et al., 2015) e subsidiar propostas de manejo que visem a sustentabilidade da atividade pesqueira na região.

A falta de acompanhamento da pesca de subsistência e comercial na unidade familiar de produção e a delimitação dos fatores que a influenciam, ao longo dos tributários do rio Amazonas, fazem parte do hiato na caracterização desta atividade na região (CARDOSO; FREITAS, 2012; LIMA et al., 2012; INOMATA; FREITAS, 2015). Diante do exposto, o rio Madeira (Rondônia) foi escolhido como estudo de caso, com os objetivos de: i) avaliar e comparar a dinâmica e a importância socioeconômica da atividade pesqueira na unidade familiar de produção em comunidades ribeirinhas e; ii) comparar a influência na composição e abundância das espécies capturadas de fatores ambientais (nível hidrológico e ambientes de pesca), distância do mercado consumidor e destino do pescado (subsistência ou comercialização).

\section{MATERIAL E MÉTODOS}

A sub-bacia do rio Madeira ocupa 20\% da área total da bacia Amazônica e é uma das regiões mais complexas do ponto de vista geográfico, com cabeceiras localizadas na região Andina (da Bolívia e do Peru) e sua maior extensão situada nas regiões amazônicas mais baixas, até 300 m de altitude (GOULDING, 1979).

Águas brancas e a existência de extenso trecho encachoeirado na sua porção média, são características marcantes desse rio (CELLA-RIBEIRO et al., 2013). As águas brancas são resultado do processo de intereperização dos sedimentos andinos, que conferem grande quantidade de elementos sólidos dissolvidos e em suspensão (SIOLI, 1968).

O potencial hidroelétrico de duas das 18 cachoeiras do rio Madeira (cachoeira do Santo Antônio e Caldeirão do Inferno) foi identificado na década de 1980 e atualmente está sendo explorado por duas grandes usinas hidroelétricas (UHE): Santo Antônio e Jirau (ELETROBRAS, 1987). As quais tiveram o início da operação e fechamento dos reservatórios em setembro 2011 e novembro 2012, respectivamente. 
A cachoeira do Teotônio, atualmente área do reservatório da UHE Santo Antônio, destacava-se antes da contrução das usinas, como uma das maiores e mais imponentes corredeiras do trecho, com efeito sobre a estrutura das comunidades ícticas da região (TORRENTE-VILARA et al., 2011).

$\mathrm{Na}$ porção à montante da cachoeira Teotônio, o rio Madeira apresenta um canal fortemente encaixado e afluentes com planícies alagáveis estreitas e dinâmica sazonal típica de igarapés. À jusante, o rio apresenta áreas típicas de planície de inundação, tornando-se mais largo e menos encaixado, assemelhandose, em parte, às áreas de planícies inundáveis da Amazônia Central (SOUZAFILHO et al., 1999).

A pesca exercida na região do rio Madeira pode ser classificada como pesca artesanal de pequena escala e apresenta caraterísticas comuns a outras áreas da Amazônia: multiespecífica, multiaparelhada e sazonal (DORIA et al., 2012). É praticada principalmente em pequenas canoas e barcos de madeira (de até $12 \mathrm{~m}$ de comprimento); com redes de emalhar (utilizadas em 45\% das capturas) e "caçoeiras" (redes de emalhar longa e alta colocada a deriva no meio do rio; utilizadas em 20\% das capturas) (DORIA et al., 2015). Os pescadores tem dedicação parcial ou exclusiva à pesca e destinam a produção à comercialização nos mercados regionais, mais ou menos distantes (CARDOSO; FREITAS, 2007; DORIA et al., 2012)

Nos limites geográficos do estado de Rondônia, o rio Madeira apresentava, em 2009, 1.552 pescadores, de acordo com os registros da Colônia de Pescadores de Porto Velho, distribuídos em 79 comunidades ribeirinhas (Correspondência oficial da Colônia de Pescadores de Porto Velho (RO), Tenente Santana - Z1, ao LIP/UNIR em 2009). Na porção do rio Madeira à jusante da cachoeira do Teotônio, estão localizadas 46 destas comunidades, com um número variado de pescadores (de 1 a 220 pescadores cada), as quais englobam cerca $72 \%$ dos pescadores registrados (1.130 pescadores) na colônia para a região. Vale ressaltar que esse valor pode ser menor, uma vez que no Brasil é comum haver diferença entre o número de pescadores registrados nas colônias e o número de pescadores realmente ativos, visto que alguns indivíduos têm atuação esporádica e outros registram-se para obter benefícios sociais (DAMASIO et al., 2015).

O Laboratório de Ictiologia e Pesca da Universidade Federal de Rondônia (LIP/UNIR), no escopo do Programa de Monitoramento da Atividade Pesqueira da Santo Antônio Energia, realizou o monitoramento comunitário da pesca na unidade familiar de produção em 24 pequenas comunidades ribeirinhas, que possuíam em média 20 pescadores registrados na Colônia de Pescadores de Porto Velho. 
A seleção dos pescadores para realizar o monitoramento comunitário da pesca na unidade familiar considerou como amostra o mínimo de $10 \%$ do número total de pescadores registrados na Colônia de Pescadores em cada comunidade, bem como a disponibilidade e o interesse de participação voluntária de cada família.

O programa iniciou em abril de 2009 com 60 famílias registradas na área à jusante da cachoeira do Teotônio. Devido à desistência e à dificuldade apresentada por alguns pescadores em realizar o próprio registro diariamente, selecionaram-se cinco comunidades (dentre as 24), considerando a qualidade dos registros durante um ciclo hidrológico, o ambiente de pesca (lacustre e/ou fluvial) e a distância de cada comunidade ao porto de desembarque pesqueiro, denominado Cai N’água, localizado na área urbana de Porto Velho (entre 50, 100 e $150 \mathrm{~km}$ de distância). As comunidades selecionadas foram Bom Jardim, Terra Caída, Boa Vitória, Papagaios e Cuniã (Figura 1 e Tabela 1).

Figura 1. Localização geográfica das comunidades alvo deste estudo

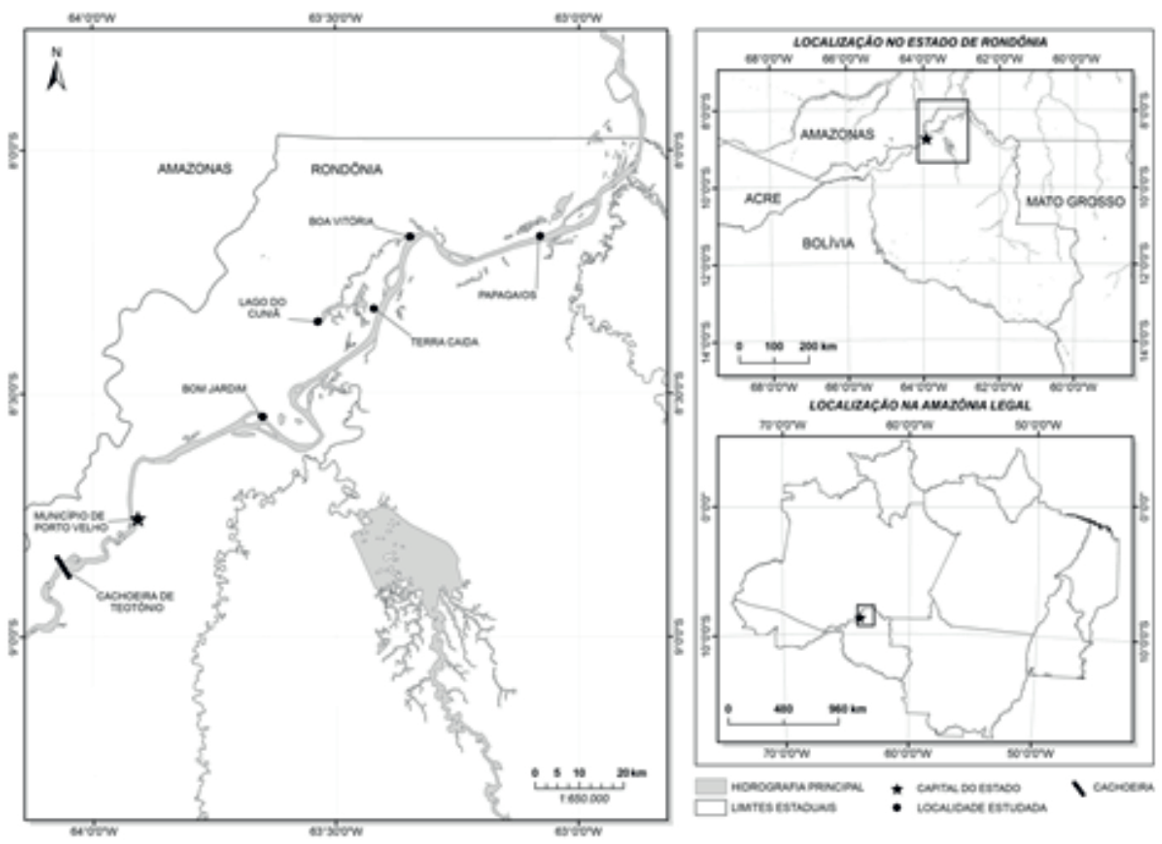


Tabela 1. Número de pescadores registrados na Colônia de Pescadores de Porto Velho nas comunidades estudadas (em 2009), número de pescadores que participaram do estudo, principal ambiente de pesca e a distância da comunidade do porto de desembarque em Porto Velho

\begin{tabular}{|l|c|c|c|c|}
\hline & \multicolumn{4}{|c|}{ Número de pescadores } \\
\hline Comunidades & $\begin{array}{c}\text { Registrados } \\
\text { na Colônia } \\
\text { de } \\
\text { Pescadores }\end{array}$ & $\begin{array}{c}\text { Participantes } \\
\text { do estudo }\end{array}$ & $\begin{array}{c}\text { Ambiente de } \\
\text { pesca }\end{array}$ & $\begin{array}{c}\text { Distância } \\
\text { do porto de } \\
\text { desembarque } \\
(\mathrm{km})\end{array}$ \\
\hline Bom Jardim & 10 & 5 & fluvial & 45,28 \\
\hline Terra Caída & 33 & 3 & fluvial, lacustre & 99,55 \\
\hline Boa Vitória & 13 & 4 & fluvial, lacustre & 120,11 \\
\hline Papagaios & 25 & 3 & fluvial, lacustre & 150,15 \\
\hline Cuniã & 80 & 8 & lacustre & 158,54 \\
\hline
\end{tabular}

Estas comunidades ribeirinhas apresentam pequeno número de habitantes (Bom Jardim, Terra Caída, Boa Vitória e Papagaios tem menos que 100 habitantes e Cuniã cerca de 400 habitantes - informação oral do chefe distrital de cada localidade). Estes habitantes vivem especialmente da agricultura de subsistência e do extrativismo vegetal e animal, com destaque para a pesca. A comunidade de Bom Jardim está às margens do rio Madeira e mais próxima do centro urbano de Porto Velho $(45,28 \mathrm{~km})$ com acesso terrestre e fluvial. As demais comunidades também estão localizadas as margens do rio Madeira, mas estão distantes do centro urbano $(\geq 100 \mathrm{~km}$ ) e possui somente acesso fluvial à Porto Velho. Cuniã está inserida na Reserva Extativista do lago Cuniã e Terra Caída está no entorno desta (Tabela 1).

Foram selecionadas 23 famílias das cinco comunidades, que corresponderam a 59 pescadores dos 161 registrados para as localidades, representando 5,3\% do total de pescadores registrados para toda a área à jusante (Tabela 1). Os pescadores e familiares receberam treinamento e material de coleta composto por: balança digital, fita métrica, lápis, borracha, caneta e fichas para os registros da captura de pescado.

O registro foi feito diariamente por um membro da família e recolhido mensalmente por um pesquisador do LIP/UNIR, no período de agosto de 2009 a julho de 2010 (anterior à construção do reservatório). Foram obtidas informações sobre as espécies capturadas e a quantidade de pescado (kg) destinado ao consumo e à comercialização. 
Para a análise da importância socioeconômica da atividade pesqueira, foram aplicados questionários semiestruturados a um membro das famílias de pescadores nas comunidades estudadas, no período de abril a outubro de 2009. As famílias entrevistadas foram escolhidas de forma aleatória e as entrevistas realizadas voluntariamente, englobando outras famílias além das selecionadas para realizar o registro diário da pesca. No total foram entrevistados 132 indivíduos, dos 161 registrados nas cinco comunidades (correspondendo a $12 \%$ dos pescadores registrados na colônia para toda a área à jusante). As questões utilizadas permitiram obter as seguintes informações: número de pessoas e pescadores por família, atividades econômicas complementares desenvolvidas e rendimento médio mensal com a pesca e com outras atividades produtivas.

A identificação taxonômica do pescado registrado pelos pescadores considerou a lista de espécies comerciais identificadas para esta região da bacia do rio Madeira por Doria et al. (2012). Quando necessário e/ou quando surgia um novo registro, os exemplares eram coletados e tinham sua classificação taxonômica confirmada pela equipe de taxonomistas do LIP/UNIR, considerando Queiroz et al. (2013). Não foi possível a identificação das espécies inseridas dentro do grupo de pescado denominado de "salada", por incluir mais de uma espécie não identificada no registro.

O consumo de pescado per capita ${ }^{-1} \cdot$ dia $^{-1}$ foi estimado com base nos dados registrados do total capturado (sem eviscerar) destinado ao consumo diário, levando em consideração o número de pessoas de cada uma das 23 famílias avaliadas. Considerando que $40 \%$ do pescado destinado ao consumo equivalem a vísceras, ossos, pele e escamas, que na maioria das vezes não são utilizados na alimentação (SMITH 1979; CERDEIRA; RUFFINO, ISAAC, 1997), excluiu-se este percentual para obtenção do consumo per capita eviscerado.

Os períodos hidrológicos na porção alta e média do rio Madeira foram estabelecidos da seguinte forma: novembro a janeiro (enchente), fevereiro a abril (cheia), maio a julho (vazante) e agosto a outubro (seca) (TORRENTE-VILARA et al., 2011). A relação entre os valores de produção mensal para as comunidades (agrupadas ou não) e o valor médio mensal das cotas hidrológicas (centímetros) do rio Madeira na estação de Porto Velho (ANA, 2013) foi analisada utilizandose o método de regressão linear simples, com auxílio do software Statistica 7.1 (STATSOFT, 2005).

A estimativa da Captura por Unidade de Esforço (CPUE) foi realizada de acordo com a equação: $\mathrm{CPUE}=\mathrm{kg}$. $(\text { família*dia })^{-1}$, onde: $\mathrm{kg}=$ produção de pescado capturado por ano; família $=$ número de famílias e dia $=$ dias de pesca. A coleta de dados não permitiu a estratificação por aparelhos de pesca, contudo 
consideramos que a maior parte das capturas na região são feitas com rede de emalhar, de acordo com Doria et al. (2015).

A diferença da CPUE entre as comunidades foi avaliada por meio de teste não paramétrico de Kruskal Wallis sobre os valores médios mensais dessa variável. A escolha deste teste foi efetuada com base no resultado de análise de normalidade e homocedasticidade dos dados, realizadas pelos testes de ShapiroWilk e de Levene, respectivamente. Todos os testes estatísticos foram realizados com auxílio do software Statistica 7.1 e o nível de significância adotado foi de $\mathrm{p}$ $<0,05$. Posteriormente foi realizado o teste post hoc Nemenyi, para verificar diferenças múltiplas entre as médias das localidades, utilizando o programa estatístico R (R DEVELOPMENT CORE TEAM, 2011).

A composição de espécies capturadas entre as comunidades foi avaliada por meio da análise de dissimilaridade. A construção da matriz de dissimilaridade entre as cinco comunidades foi realizada por meio do coeficiente de Bray Curtis para os dados de produção (kg) anual das espécies para cada comunidade. Estes valores de produção foram extraídos do banco de dados on-line e organizados em planilha eletrônica e posteriormente utilizados no software Palaeontological Statistics (PAST) (HAMMER; HARPER; RIAN, 2001).

\section{RESULTADOS}

A análise dos questionários do perfil socioeconômico indicou que as famílias são formadas em média por 5,28 indivíduos e destes, dois são pescadores. Os pescadores se dedicaram à pesca em média 15,3 dias por mês, entretanto os valores variaram entre as famílias e entre as comunidades. Estas variações foram observadas também para a renda declarada, que foi em média $\mathrm{R} \$ 408,07$ para a pesca e $\mathrm{R} \$ 485,41$ para outras atividades econômicas (como agricultura, por exemplo). As comunidades de Terra Caída e Papagaios apresentaram os maiores valores de renda obtidos com a pesca e com outras atividades. Considerando as comunidades agrupadas a pesca correspondeu aproximadamente a $40 \%$ da renda familiar. Os pescadores, em sua maioria (78\%), declararam que a agricultura era a principal alternativa de renda exercida em conjunto com a pesca (Tabela 2). 
Tabela 2. Perfil da família do pescador quanto ao número de pessoas da família (número de pescadores na família), média do total de dias dedicados à pesca por família mensalmente; renda média declarada obtida com a pesca e com outras atividades e frequência (\%) de entrevistados que se dedicam a agricultura

\begin{tabular}{|c|c|c|c|c|c|c|}
\hline \multirow{2}{*}{$\begin{array}{l}\text { Comunida- } \\
\text { des }\end{array}$} & \multirow{2}{*}{$\begin{array}{l}\text { Entre- } \\
\text { vistados } \\
(\mathrm{N})\end{array}$} & \multirow{2}{*}{$\begin{array}{c}\text { Número } \\
\text { de pessoas } \\
\text { da família } \\
\text { (pescadores) }\end{array}$} & \multirow{2}{*}{$\begin{array}{l}\text { Média } \\
\text { de dias } \\
\text { de pesca: } \\
\text { família }^{-1} \\
\text { mês }^{-1}\end{array}$} & \multicolumn{2}{|c|}{$\begin{array}{c}\text { Renda média } \\
\text { declarada }\end{array}$} & \multirow{2}{*}{$\begin{array}{l}\text { Frequên- } \\
\text { cia }(\%) \text { de } \\
\text { entrevistados } \\
\text { dedicados à } \\
\text { agricultura }\end{array}$} \\
\hline & & & & $\begin{array}{c}\text { Pesca } \\
(\mathrm{R} \$)\end{array}$ & \begin{tabular}{|c|} 
Outras \\
atividades \\
$(\mathrm{R} \$)$
\end{tabular} & \\
\hline Bom Jardim & 15 & $6(2)$ & 14.22 & 396,66 & 591,81 & 73 \\
\hline Cuniã & 55 & $5(2)$ & 16.47 & 273,27 & 297,62 & 68 \\
\hline Terra Caída & 24 & $5(2)$ & 14.16 & 720,62 & 783,25 & 83 \\
\hline Boa Vitória & 17 & $5(2)$ & 17.35 & 267,64 & 302,81 & 89 \\
\hline Papagaios & 21 & $5(2)$ & 14.22 & 535,75 & 785,90 & 75 \\
\hline $\begin{array}{l}\text { Média total } \\
\text { (D.P.) }\end{array}$ & & $5,28(2)$ & 15,3 & $\begin{array}{r}408,70 \\
( \pm 212,13) \\
\end{array}$ & $\begin{array}{r}485,41 \\
( \pm 282,84) \\
\end{array}$ & 78 \\
\hline
\end{tabular}

A Produção Média Anual (PMA) das famílias amostradas no período de estudo foi de $2.403 \mathrm{~kg}$. família ${ }^{-1} \cdot \mathrm{ano}^{-1}(\mathrm{~N}=23 \pm 2.261)$, com média mensal de $220 \mathrm{~kg}$. família ${ }^{-1} \cdot \mathrm{mês}^{-1}\left(\mathrm{~N}=235 \pm 430 \mathrm{~kg}\right.$. família $\left.{ }^{-1} \cdot \mathrm{mês}^{-1}\right)$. Entre as comunidades a PMA foi diferente com destaque para Terra caída que apresentou maiores valores (Figura 2 e Tabela 3). Terra Caída também apresentou o maior valor da CPUE 55,7 kg.familia ${ }^{-1}$. dia ${ }^{-1}$. Entre os menores valores estão as comunidades de Papagaios e Cuniã que registraram 3,7 e 3,2 kg. familia ${ }^{-1}$. dia $^{-1}$, respectivamente (Figura 3). Os valores de mediana da CPUE entre as comunidades variaram de 6,88 a $34 \mathrm{~kg}$. familia ${ }^{-1} \cdot$ dia $^{-1}$. O teste de Kruskal Wallis comprovou diferença entre as comunidades para a CPUE, com os maiores valores observados em Terra Caída (Kruskal H = 29,51; p < 0,001) (Figura 2). E de acordo com o teste post hoc Nemenyi, os valores médios tanto de produção $(\mathrm{kg})$ quanto CPUE de Terra Caída $(\mathrm{p}<0,005)$ diferiram de todas as demais localidades. Outra diferença observada foi que Cuniã apresentou médias de produções $(\mathrm{kg})$ maiores $(\mathrm{p}<0,005)$ que Bom Jardim.

A captura mensal para todas as comunidades variou em função do nível hidrológico e apresentou picos de produção entre os meses de agosto e outubro de 2009 e de maio a julho de 2010, correspondendo aos períodos de seca e vazante, respectivamente $\left(\mathrm{R}^{2}=0,60 ; \mathrm{p}<0,005\right)$ (Figura $2 \mathrm{~A}$ ). 
Figura 2. Mediana, desvio padrão e mínimo e máximo da (A) produção (kg) H:63 $\mathrm{P}<0,001$ e (B) Captura por Unidade de Esforço (kg/família*dia) H:79 P<0,001 das comunidades acompanhadas durante o período de agosto de 2009 a julho de 2010.
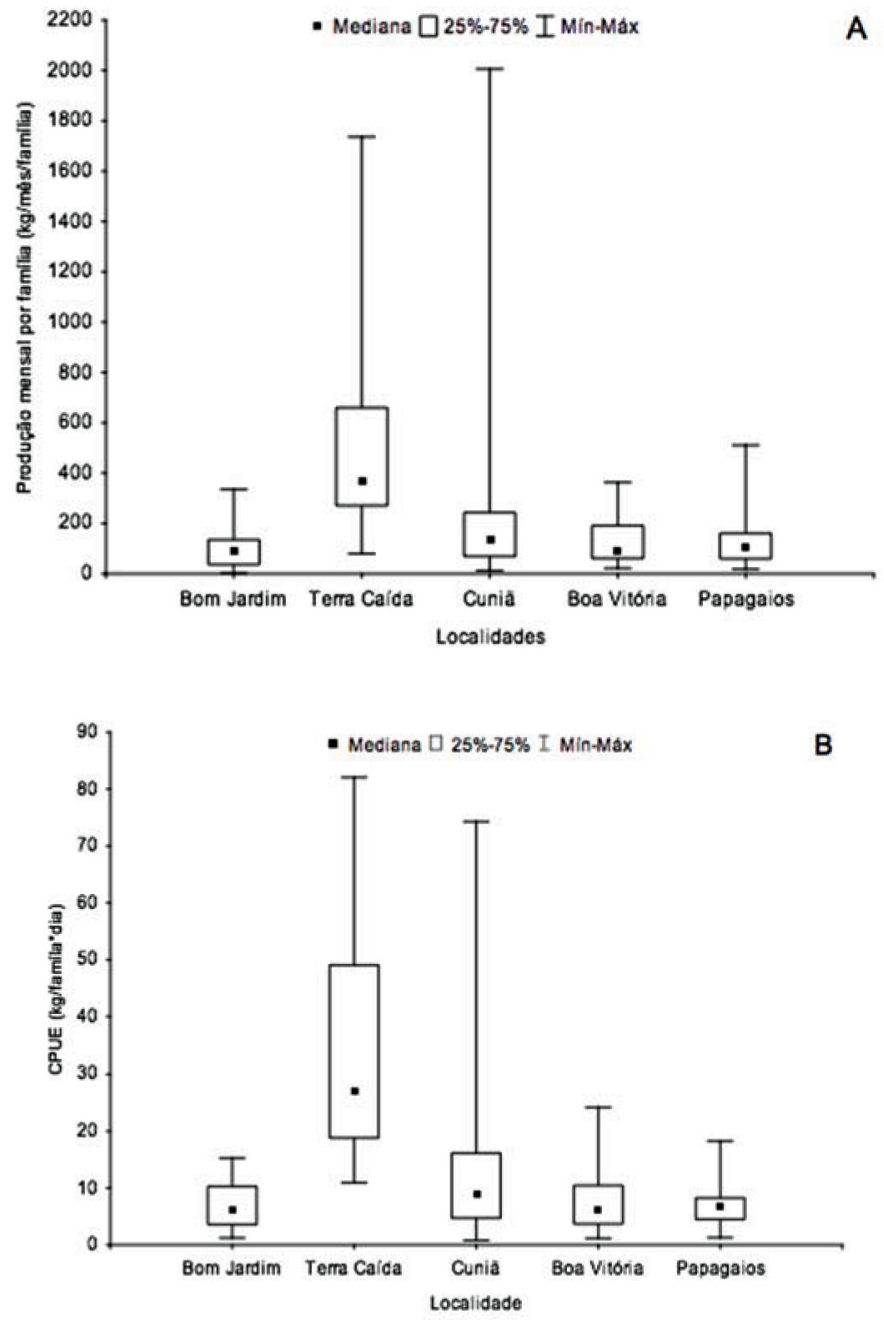

Quando as comunidades foram avaliadas separadamente, esse padrão se repete em Terra Caída, na qual a relação foi significativa $\left(R^{2}=0,65 ; p<0,001\right.$; Figura 2E) e para a comunidade do Cuniã, apesar de não apresentar diferença significativa $\left(\mathrm{R}^{2}=0,20 ; \mathrm{p}>0,05\right)$. Nas demais comunidades, a captura foi menor $\mathrm{e}$ não apresentou variações acentuadas ao longo do ano, o que pode justificar o fato da relação não ter sido significativa (Boa Vitória, $R^{2}=-0,03$; $>>0,05$; Bom Jardim, 
$\mathrm{R}^{2}=0,02 ; \mathrm{p}>0,05 ;$ Papagaios $\left.\mathrm{R}^{2}=0,03 ; \mathrm{p}>0,05\right)$. O nível hidrológico apresentou menor cota no mês de setembro $(476,5 \mathrm{~cm})$ e maior valor no mês de março (1.498,0 cm) (Figura 3).

A produção média mensal das comunidades localizadas nas margens do rio Madeira, seu principal ambiente de pesca, apresentou variações sazonais semelhantes, em que os maiores volumes de captura ocorrem entre os meses de agosto a dezembro, período de transição entre vazante e enchente. Já a comunidade do Cuniã, localizada nas margens do lago Cuniã, apresentou maior valor de produção no mês de julho e menor em dezembro, períodos de vazante e enchente, respectivamente (Figura 3).

Figura 3. Produção mensal total nas cinco comunidades estudadas (T'T) e produção média mensal em cada comunidade, (BJ) Bom Jardim; (TC) Terra Caída; (BV) Boa Vitória; (PP) Papagaios e (CN) Cuniã, no período de agosto de 2009 a julho de 2010
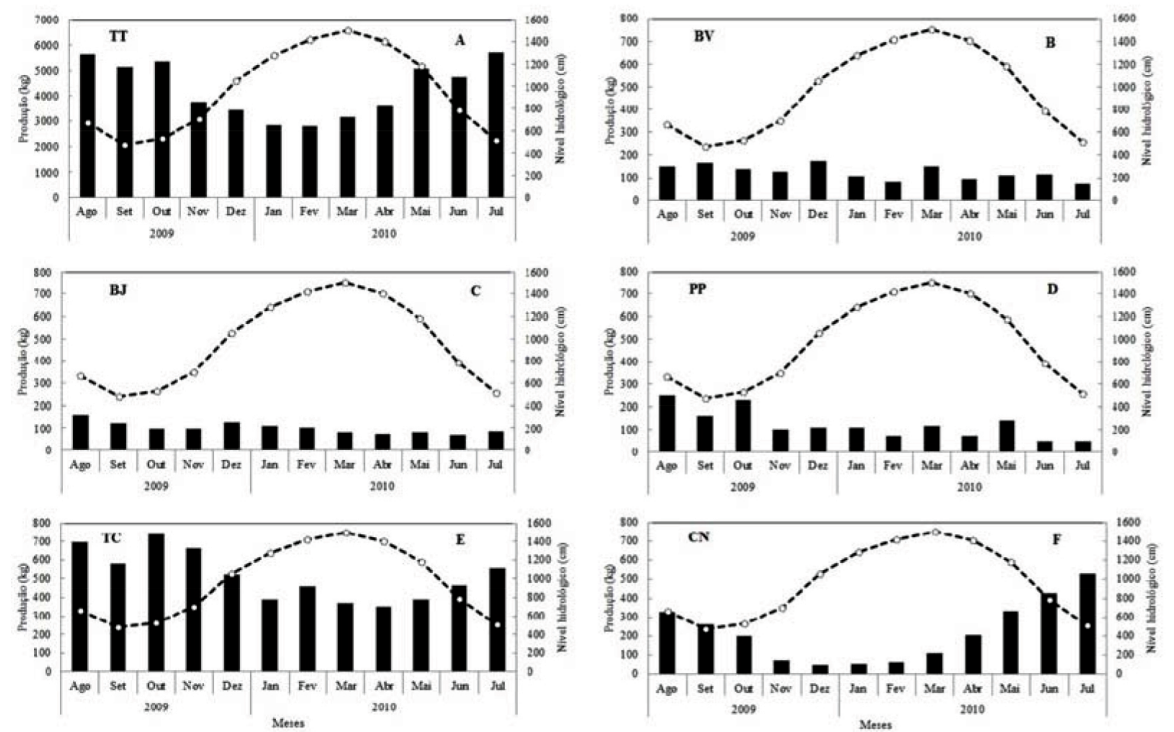

Considerando todas as comunidades, a média percentual de pescado destinado para comercialização foi $81 \%$ da captura registrada por família, e 19\% foi destinado ao consumo. O consumo per capita médio foi de 440 g.dia ${ }^{-1}$, mas se considerado o peso do pescado eviscerado esse valor decresce para 320 g.dia ${ }^{-1}$. O que representa um consumo per capita de 83,22 $\mathrm{kg}$ pescado por ano. Avaliando as localidades separadamente, observou-se diferenças numéricas tanto no consumo per capita diário quanto nos percentuais destinados à subsitência e à comercialização. As localidades de Terra Caída e Papagaios apresentaram os 
maiores valores de percentual da captura destinada à comercialização. Enquanto que o maior valor de consumo per capita diária foi observado na comunidade do Cuniã (Tabela 3).

Tabela 3. Percentual da captura destinada à comercialização e à subsistência, e consumo per capita diário médio (g.dia ${ }^{-1}$ ) por localidade estudada

\begin{tabular}{|l|r|r|r|r|r|r|}
\hline \multirow{2}{*}{ Variável } & \multicolumn{7}{|c|}{ Localidades } \\
\cline { 2 - 8 } & $\begin{array}{c}\text { Bom } \\
\text { Jardim }\end{array}$ & $\begin{array}{c}\text { Terra } \\
\text { Caída }\end{array}$ & $\begin{array}{c}\text { Boa } \\
\text { Vitória }\end{array}$ & Papagaios & Cuniã & Média \\
\hline $\begin{array}{l}\text { Produção anual por } \\
\text { família (kg) média }\end{array}$ & 1151 & 5835 & 2266 & 1471 & 1293 & 2403 \\
\hline $\begin{array}{l}\text { Percentual da captura } \\
\text { destinado (\%): }\end{array}$ & & & & & & \\
\hline Comercialização & 60 & 96 & 76 & 93 & 80 & 81 \\
\hline Consumo & 40 & 4 & 24 & 7 & 20 & 19 \\
\hline $\begin{array}{l}\text { Consumo per capita } \\
\text { diário médio (g.dia-1) }\end{array}$ & 0,46 & 0,27 & 0,44 & 0,32 & 0,71 & 0,44 \\
\hline
\end{tabular}

Nota: Os maiores valores estão em negrito

Durante o período estudado, foram citadas 43 espécies ou grupo de espécies nos registros de captura entre as comunidades acompanhadas (Apêndice 1). O número de espécies capturadas variou de acordo com a comunidade avaliada, evidenciando a especificidade das pescarias. A comunidade com maior número de espécies foi Bom Jardim, com total de 32 espécies, seguida por Boa Vitória com 29, Cuniã com 25, Terra Caída com 23 e Papagaios com 20.

A ordem dos Siluriformes foi a mais representativa nas comunidades de Bom Jardim, Boa Vitória e Papagaios representando, respectivamente, 63\%, 53\% e 84\% da captura. Já as ordens dos Characiformes e Perciformes foram mais importantes nas comunidades com pesca em ambiente lacustre: Terra Caída e Cuniã. Na primeira, $48 \%$ e $32 \%$ da captura foram espécies de Characiformes e Perciformes, respectivamente, e no Cuniã estes grupos representaram 53\% e $24 \%$ da captura.

De modo geral, nove espécies ou grupos de espécies foram responsáveis por cerca de 70\% da captura total (Figura 4). Entre os Siluriformes, destacaram-se a dourada (Brachyplatystoma rousseauxii), com maiores capturas em Papagaios (1,9 t) e em Boa Vitória (1,3 t); o filhote (Brachyplatystoma filamentosum), em Papagaios $(1,0$ t) e em Boa Vitória (0,5 t) e o surubim (Psendoplatystoma faciatum) em Terra Caída (1,7 t) e Bom Jardim (0,3 t). Dentre os Characiformes destacaram-se a curimatã (Prochilodus nigricans) no Cuniã e em Terra Caída, onde foram registrados 2,60 e 2,5 t da espécie, respectivamente; o pacu comum (Mylossoma duriventre) 
em Terra Caída (2,6 t), no Cuniã $(1,9)$ e em Boa Vitória (1,3 t). A jatuarana (Brycon amazonicus) foi a espécie mais capturada no Cuniã, com 1,5 t. Entre os Perciformes, destacaram-se o tucunaré-açú (Cichla pleiozona) em Terra Caída e no Cuniã, onde foram capturados 1,4 e 3,6 t, respectivamente; o acará (Astronotus sp) em Terra Caída correspondeu a 4 t e no Cuniã 0,8 t. O pirarucu (Arapaima gigas) foi destaque no Cuniã com captura de 2,7 t, demonstrando sua importância econômica para a comunidade.

Figura 4. Produção total (kg) das 9 espécies mais capturadas pelas famílias por comunidades, durante o período de agosto de 2009 a julho de 2010

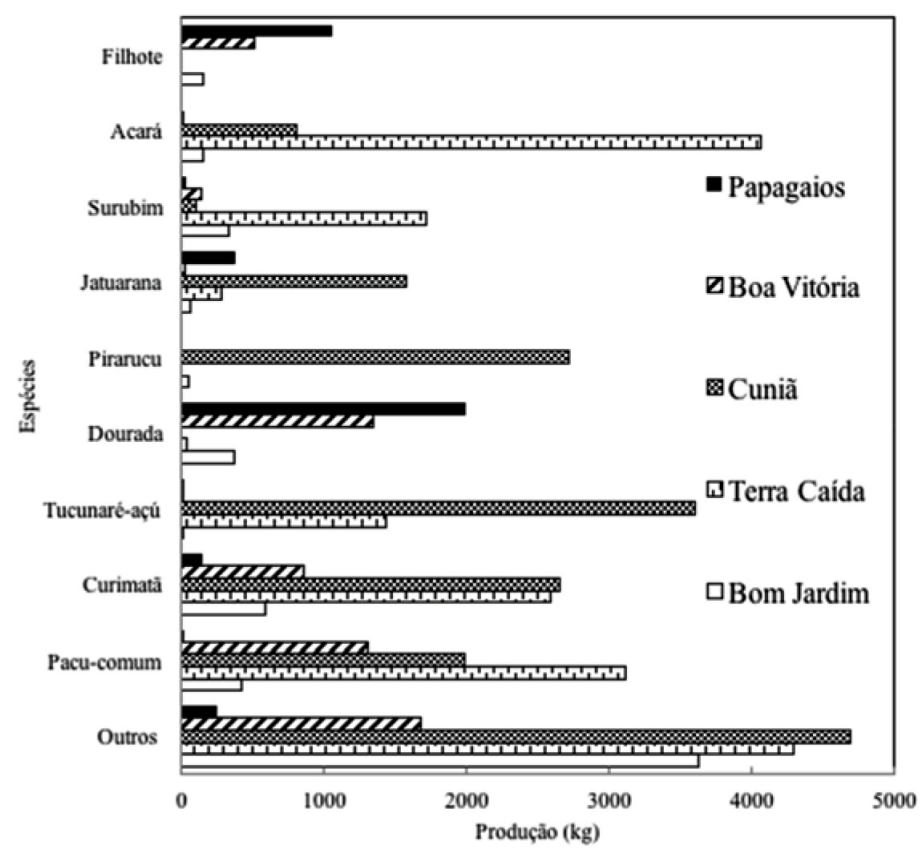

A análise da composição específica entre as comunidades, levando em consideração os dados de produção $(\mathrm{kg})$ por espécie, resultou na formação de dois grupos principais e um subgrupo. O primeiro grupo foi composto por Terra Caída e Cuniã (próximo ao nível de similaridade de 56\%) e o segundo grupo foi formado por Papagaios, Boa Vitória e Bom Jardim (próximo ao nível de similaridade de $33 \%$ ). Estas duas últimas comunidades formaram um subgrupo com nível de similaridade próximo de 45\% (Figura 5). Os agrupamentos não refletem a distância das comunidades com o mercado consumidor, visto que comunidades mais distantes como Papagaios e Boa Vitória estão agrupadas com a comunidade mais próxima do centro urbano de Porto Velho, que é Bom Jardim (Tabela 1). 
A análise sazonal da composição das capturas, considerando o grupo com maior representatividade nas capturas nas comunidades estudadas (espécies com produção $>1 \%$ da captura total), mostrou que houve variações entre os períodos hidrológicos (Tabela 4). O pacu e o curimatã ocorrem e são predominantes durante o ano todo, porém a captura do pacu foi maior durante a enchente do rio, e a do curimatã durante a vazante. Outras espécies têm os maiores valores de captura limitados a alguns períodos. A dourada, por exemplo, apresentou maior valor de captura no período da enchente; o tucunaré na cheia e na vazante e o pirarucu na vazante e na seca.

Figura 5. Análise de agrupamento para valores de dissimilaridade na composição da produção específica nas comunidades de Terra Caída (TC), Cuniã (CN), Boa Vitória (BV), Bom Jardim (BJ) e Papagaios (PP). Coeficiente de correlação cofenética $r_{c}=0.86$

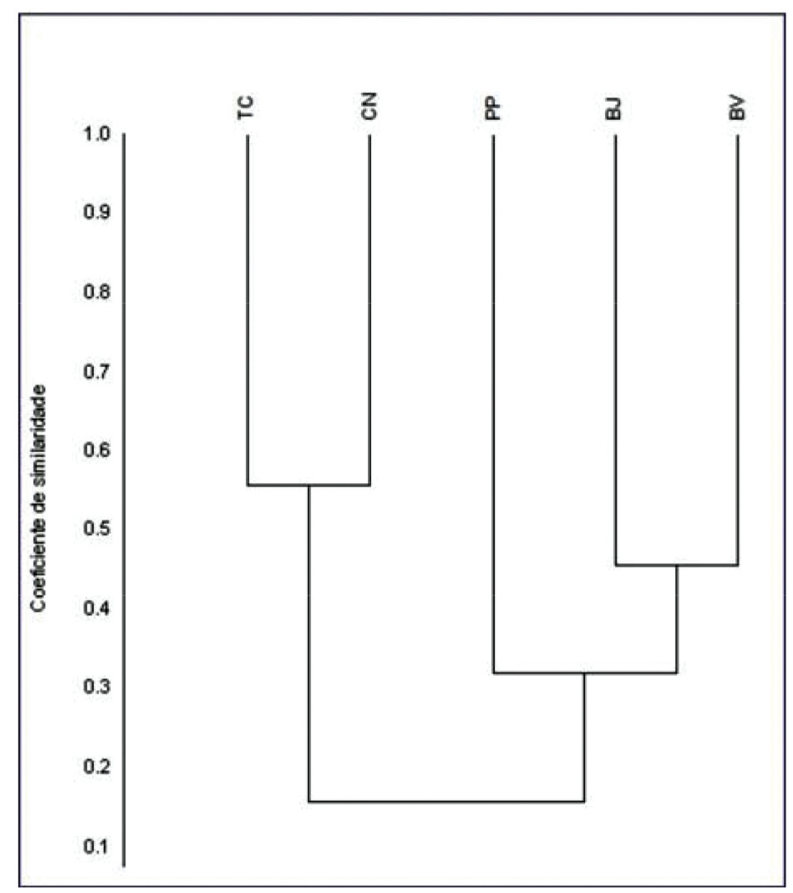


Tabela 4. Variação sazonal por período hidrológico da composição das capturas, produção específica $(\mathrm{kg})$ e percentual, registrada nas comunidade estudadas

\begin{tabular}{|l|r|r|r|r|r|r|r|r|}
\hline \multirow{2}{*}{$\begin{array}{c}\text { Categoria de } \\
\text { pescado }\end{array}$} & \multicolumn{2}{|c|}{ Seca } & \multicolumn{2}{c|}{ Enchente } & \multicolumn{2}{c|}{ Cheia } & \multicolumn{2}{c|}{ Vazante } \\
\cline { 2 - 9 } & $\mathrm{kg}$ & \multicolumn{1}{c}{$\%$} & $\mathrm{~kg}$ & $\%$ & $\mathrm{~kg}$ & $\%$ & $\mathrm{~kg}$ & \multicolumn{1}{c}{$\%$} \\
\hline Pacu-comum & 1464 & 11 & 1.383 & 20 & 1972 & 13 & 2025 & 13 \\
\hline Curimatã & 1480 & 11 & 491 & 7 & 1893 & 13 & 2964 & 18 \\
\hline Tucunaré-açu & 852 & 7 & 182 & 3 & 1426 & 9 & 2591 & 16 \\
\hline Acará & 1363 & 10 & 641 & 9 & 2135 & 14 & 891 & 6 \\
\hline Dourada & 919 & 7 & 1.567 & 23 & 590 & 4 & 662 & 4 \\
\hline Pirarucu & 1361 & 10 & 42 & 1 & 0 & - & 1370 & 8 \\
\hline Jatuarana & 449 & 3 & 73 & 1 & 1243 & 8 & 569 & 4 \\
\hline Surubim & 364 & 3 & 111 & 2 & 895 & 6 & 935 & 6 \\
\hline Filhote & 890 & 7 & 367 & 5 & 187 & 1 & 279 & 2 \\
\hline Outras & 3922 & 30 & 1.980 & 29 & 4763 & 32 & 3852 & 24 \\
\hline Produção total & 13064 & & 6836 & & 15103 & & 16138 & \\
\hline
\end{tabular}

$\mathrm{Na}$ análise da produção total $(\mathrm{kg})$ e relativa (\%) das categorias de pescado destinadas ao consumo e à comercialização nas comunidades estudadas, observouse que algumas categorias são destinadas exclusivamente à comercialização especialmente as representantes do grupo dos bagres Siluriformes (douradaBrachyplatystoma rousseauxii; fillhote - Brachyplatystoma filamentosum) e o pirarucu (Araipama gigas). Dentre as categorias destinadas exclusivamente ao consumo estão a piranha (Serrasalmus sp.) e o mandi (Pimelodus aff. blochii).

Tabela 5. Produção total $(\mathrm{kg})$ e relativa $(\%)$ das categorias de pescado destindas a subsistência e à comercialização nas comunidades estudadas

\begin{tabular}{l|r|r|r|r}
\hline \multirow{2}{*}{ Categoria de pescado } & \multicolumn{5}{|c|}{ Destino da produção (kg) } \\
\cline { 2 - 6 } & Subsistência & $\%$ & Comercialização & \multicolumn{1}{c}{$\%$} \\
\hline Acará & 86 & 5 & 1763 & 95 \\
Acará-açu & 55 & 2 & 2156 & 98 \\
Barba chata & 341 & 32 & 729 & 68 \\
Curimatã & 1144 & 17 & 5683 & 83 \\
Dourada & & 0 & 3641 & 100 \\
Filhote & & 0 & 1549 & 100 \\
Jatuarana & 489 & 25 & 1464 & 75 \\
Mandi & 520 & 100 & & 0 \\
Pacu-comum & 1509 & 23 & 5140 & 77 \\
Piramutaba & 186 & 44 & 239 & 56 \\
Piranha & 354 & 100 & & 0 \\
Pirarara & & 0 & 530 & 100 \\
Pirarucu & & 0 & 2576 & 100 \\
Surubim & 26 & 1 & 1898 & 99 \\
Tucunaré-açu & 695 & 19 & 2905 & 81 \\
\hline
\end{tabular}




\section{DISCUSSÃO}

A importância econômica e social da pesca para as famílias que vivem nas comunidades ribeirinhas do rio Madeira foi ressaltada no número de pescadores por família, número de dias dedicados mensalmente à atividade, renda gerada com a atividade e a representatividade desse valor na renda familiar. $O$ valor médio da renda declarada obtida com a pesca $(\mathrm{R} \$ 408,70 \pm 212,13)$ foi semelhante ao salário mínimo oficial no país para o mesmo ano (R\$465,00) (IBGE, 2014), o que atraiu grande contingente de trabalhadores para a atividade (em 2009 haviam aproximadamente 1.500 pescadores registrados na Colônia de Pescadores de Porto Velho).

A dependência do pescado para a subsistência e a importância deste para assegurar uma boa alimentação a baixo custo são observadas nos altos valores de consumo per capita diário e anual. Esses são maiores que os recomendadas pela Organização Mundial de Saúde (12 kg pescado por ano per capita) e semelhantes aos observados em outras regiões da Amazônia (CERDEIRA et al., 1997; ISAAC; ALMEIDA, 2011).

A complementação da renda familiar dos pescadores com a agricultura é comum em comunidades ribeirinhas na região do rio Madeira (LIMA; DORIA; FEITAS, 2012). Essa característica pode determinar de forma positiva a diversidade econômica e a qualidade de vida desses trabalhadores polivalentes, os quais associam outras atividades à pesca, comercializando vários produtos com o objetivo de obter uma renda mínima (FURTADO, 1993). Além disso, destacase a sua importância devido à acentuada sazonalidade da produção pesqueira na região Amazônica (JUNK et al., 1989).

As comunidades avaliadas no presente estudo mostraram diferenças na abundância e composição da captura destinadas ao consumo e à comercialização determinadas por diferentes fatores. A sazonalidade observada na produção total e na composição da captura refletem as variações no nível hidrológico que afetam o comportamento migratório, a disponibilidade e a densidade das populações de peixes (ISAAC et al., 2000) e demonstram a adaptação do homem amazônico as variações do meio (ISAAC et al., 2015). Esta influência era esperada visto que representa o padrão amazônico para pesca de pequena escala. Na Amazônia, é comum observar baixa produção nos meses em que os níveis dos rios estão mais altos e os peixes mais dispersos na planície alagada; e elevada produção no período em que as águas dos rios encontram-se na vazante e na seca (BATISTA; ISAAC; VIANA, 2004; CARDOSO; FREITAS, 2007; GONÇALVES; BATISTA, 2008). Nas localidades de Terra Caída e Papagaios, que têm como principal destino da 
captura a comercialização do pescado, esse padrão se manteve, há uma harmonia entre a pesca e o ciclo hidrológico, com o foco na captura de espécies de maior valor comercial com os siluriformes.

Essa diminuição na captura pode estar relacionada à baixa frequência de cardumes nos rios ou ser decorrência do defeso, imposto por órgãos de regulamentação, que não permitem a captura de várias espécies em tamanho comercial (CARDOSO; FREITAS, 2007). A comunidade do Cuniã obteve maior registro de produção no período da vazante, fato que pode estar relacionado ao período de proibição da pesca determinada exclusivamente para essa comunidade nos meses do período de cheia (ICMBio, 2013).

Os ambientes de pesca lacustre e a proximidade com as áreas de proteção foram determinantes nos altos valores de rendimento pesqueiro das comunidades de Terra Caída e Cuniã, ressaltando a importância desses ambientes e a sua conservação. Os ambientes de pesca também determinaram a composição específica das capturas e a similaridade entre as comunidades do Cuniã e Terra Caída, principalmente em função do compartilhamento do lago Cuniã e da captura de espécies lacustres como o tucunaré-açu (Cichla pleiozona) e o acará (Astronotus sp).

O destino final do pescado parece também determinar a composição das capturas. Localidades como Bom Jardim e Boa Vitória, que apresentaram os maiores valores percentuais da captura destinada ao consumo e altos valores de consumo per capita, foram agrupadas na análise de dissimilaridade e apresentaram grande diversidade de espécies capturadas e compartilhadas. Isso porque na pesca de subsistência o pescador utliza-se de diferentes estratégias, buscando ter sempre o alimento, capturando maior número de espécies. Altos valores de consumo do pescado, como no caso do Cuniã, podem também estar associados à existência de áreas protegidas na localidade, que garantem segurança alimentar às populações e ao isolamento desta comunidade dos grandes centros (ISAAC et al., 2015).

A pesca multiespecífica observada nas pescarias das famílias estudadas é outro padrão amazônico, que se repete na região (DORIA et al., 2012). Os Siluriformes se destacam pelo maior valor econômico obtido por biomassa de pescado (em 2010, o valor de venda médio do quilograma dos siluriformes foi de R \$ 5,6 - US\$ 3,18 aproximadamente, 57\% maior que o valor médio observado para Characiformes; Banco de dados LIP/UNIR), já os Characifomes se destacam pela quantidade de biomassa vendida (aproximadamente 56\% maior que Siluriformes). Contudo, há preferência na captura e comercialização de espécies de alto valor comercial, especialmente dos Siluriformes (dourada - 
Brachyplatystoma rousseauxï; fillhote - Brachyplatystoma filamentosum) e Characiformes de valor mediano (pacu comum - Mylossoma duriventre; curimatã - Prochilodus nigricans e jatuarana - Brycon amazonicus). Estas espécies são também consumidas em menor proporção e em conjunto com outras espécies que não são destinadas a venda. $\mathrm{O}$ que pode ser um indicador do bom estado de conservação do estoque, no período pré-barramento, isto porque que o consumo e a venda das mesmas espécies podem indicar alta abundância e disponibilidade desses peixes no ambiente.

A distância das comunidades pesqueiras aos grandes centros urbanos pode também influenciar a composição e a captura da pesca realizada pelas famílias ribeirinhas. Inicialmente esperava-se que as comunidades mais próximas ao centro urbano de Porto Velho apresentassem menores valores de captura e de consumo do pescado, tendo em vista a possiblidade de participarem mais sistematicamente dos mercados urbanos e com isso dependerem menos dos recursos naturais (ISAAC et al., 2015). Porém, os resultados observados não confirmaram a hipótese de que quanto mais urbano menor o consumo do pescado. Na comunidade mais próxima à Porto Velho, Bom Jardim, com acesso tanto fluvial como terrestre à área urbana do município, as famílias avaliadas apresentaram valores de consumo per capita semelhante às comunidades distantes, apesar de baixos valores de captura por família e renda obtida com a pesca em relação as demais atividades (agricultura). Essa proximidade do centro urbano foi aproveitada para diversificação de produtos para comercialização, associando o pescado aos produtos agriculturáveis. Já as famílias mais distantes dos centros urbanos parecem investir no aumento da sua captura mensal (e.g.: Terra Caída) e em peixes de maior valor comercial (e.g.: Papagaios), obtendo produtos com maior valor agregado por quilo, mais fácil de sererem vendidos e que justifiquem o deslocamento de longas distâncias para a comercialização.

\section{CONCLUSÃO}

A rentabilidade da pesca associada à necessidade de subsistência e de geração de renda e/ou a falta de alternativas econômicas, reforçam a importância da atividade para as famílias ribeirinhas do rio Madeira. A produção pesqueira e a composição específica nessas comunidades refletem o destino final da captura, o ambiente de pesca, as variações do ciclo hidrológico, e a distância dos grandes centros. De maneira geral, as comunidades mais distantes estão em locais mais preservados, a maioria delas associadas a ambientes lacustres, e apresentam altos valores de consumo per capita de pescado. Estas quando tem como destino 
principal a comercialização do pescado, apresentam captura fortemente sazonal, influenciada pelo ciclo hidrológico e focada em peixes de maior valor comercial. Nas comunidades mais próximas dos centros urbanos o destino do pescado é principalmente para subsistência, e a pesca está associada a outras atividades econômicas.

Estes resultados servirão como marco histórico para comparações posteriores, frente às futuras modificações que poderão ocorrer com a implantação de grandes empreendimentos na região. Além disso, mostraram que o monitoramento comunitário de variáveis simples de serem registradas como abundância, composição e destino das capturadas podem ser utilizadas como importante ferramenta para o avaliação dinâmica da atividade pesqueira e o estado de conservação dos recursos pesqueiros em comunidades remotas da Amazônia.

\section{AGRADECIMENTOS}

Aos pescadores e seus familiares que gentilmente colaboraram com esse estudo. À Santo Antônio Energia e ao IEPAGRO pelo apoio logístico e financeiro à pesquisa. A primeira autora agradece ao CNPq pela bolsa Ciências Sem Fronteiras; à CAPES, pelo apoio aos projetos no 038/13: Rede Cooperação Internacional Pesquisa Integrativa Efeitos Socioambientais de Barragens Hidroelétricas na Amazônia Legal e projeto n⿳ำ 021/2012: Pró-Amazônia: Biodiversidade e Conservação. $\mathrm{E}$ as últimas autoras agradecem a CAPES pela bolsa de pesquisa.

\section{REFERÊNCIAS}

ANA - Agência Nacional de Águas. 2013. Disponível em: www.ana.gov.br. Acesso em: 20 out. 2013.

BATISTA, V. S.; ISAAC, V. J.; VIANA, J. P. Exploração e manejo dos recursos pesqueiros da Amazônia. In: RUFFINO, M. L. (Org.). A pesca e os recursos pesqueiros na Amazônia brasileira. Manaus: IBAMA/ProVárzea, 2004. p. 63152.

BRASIL. Decreto $\mathrm{n}^{-}$6.040, de 7 de fevereiro de 2007. Fica instituída a Política Nacional de Desenvolvimento Sustentável dos Povos e Comunidades Tradicionais - PNPCT. Diário Oficial da União, Brasília, 08 de fevereiro 2007. Seção 1, p. 316. 
CARDOSO, R. S.; FREITAS, C. E. C. Desembarque e esforço de pesca da frota pesqueira comercial de Manicoré (Médio Rio Madeira), Amazonas, Brasil. Acta Amazonica, Manaus, v. 37, p. 605-612, 2007.

CARDOSO, R.S.; FREITAS, C.E. The commercial fishing fleet using middle stretch of the Madeira river, Brazil. Acta Scientiarum. Biological Sciences, Maringá-PR, v. 3, p. 247-253, 2012.

CELLA-RIBEIRO, A.; TORRENTE-VILARA， G.; HUNGRIA， D.B.; OLIVEIRA, M. As corredeiras do Rio Madeira. In: QUEIROZ, L. J.; TORRENTE-VILARA, G.; OHARA, W. O.; PIRES, T. H.; ZUANON, J.; DORIA, C. R. C. (Org.). Peixes do Rio Madeira. 1. ed. São Paulo: Dialeto, 2013. v. 1, p. 56-63.

CERDEIRA, R. G. P.; RUFFINO, M. L.; ISAAC, V. J. Consumo de pescado e outros alimentos pela população ribeirinha do lago Grande de Monte Alegre, PA - Brasil. Acta Amazonica, Manaus, v. 27, p. 213-228, 1997.

DA COSTA, T. V.; SILVA, R. R. S.; SOUZA, J. L.; BATALHA, O. S.; HOSHIBAA, M. A. Aspectos do consumo e comércio de pescado em Parintins. Bol. Inst. Pesca, São Paulo, v. 39, n. 1, p. 63-75, 2013.

DAMASIO, L. M. A.; LOPES, P. F. M.; GUARIENTO, R. D.; CARVALHO, A. R. Matching Fishers' Knowledge and Landing Data to Overcome Data Missing in Small-Scale Fisheries. 2015. PLoS ONE, v. 10, n. 7, : e0133122. doi:10.1371/ journal.pone.0133122

DORIA, C. R. C.; RUfFINO, M. L.; HIJAZI, N. C.; CRUZ, R. L. A Pesca comercial na bacia do Rio Madeira, estado de Rondônia, Brasil. Acta Amazonica, Manaus, v. 42, p. 29-40, 2012.

ELETROBRAS. Plano 2010: Relatório Geral Plano Nacional de Energia Elétrica 1987/2010. Brasília, 1987. 269p.

FABRÉ, N. N.; ALONSO, J. C. Recursos Ícticos no Alto Amazonas: Sua importância para populações ribeirinhas. Boletim Museu Paraense Emílio Goeldi, Zoologia, Belém, v.1, p. 19-55, 1998.

FURTADO, L. G. Pescadores do rio Amazonas: um estudo antropológico da pesca ribeirinha numa área amazônica. Belém: CNPQ/MPEG, 1993. 486p.

GONÇALVES, C.; BATISTA, V.S. Avaliação do desembarque pesqueiro efetuado em Manacapuru, Amazônia Central. Acta Amazonica, Manaus, v. 38, p. 135-144, 2008. 
GOULDING, R. M. Ecologia da pesca do rio Madeira. Manaus: CNPQ-INPA, 1979. 172p.

HAMMER, O.; HARPER, D. A. T.; RIAN, P. D. Past: Palaeonthological statistics software package for education and data analysis. Version. 1.37. 2001. Disponível em: <http://palaeo-electronica.org/2001_1/past/issue1_01.htm>. Acesso em: 12 nov. 2012.

IBGE - Instituto Brasileiro de Geografia e Estatística. Disponível em: http:/ / www.ibge.gov.br/> Acesso em: 12 out. 2014.

ICMBIO - Instituto Chico Mendes de Conservação da Biodiversidade. Acordo de gestão da reserva extrativista do lago do cuniã, município de porto velho, estado de Rondônia. Portaria $n^{\circ}$ 208, de 10 de julho de 2013. Diário Oficial da União - Seção 1, no 136, 17 de julho de 2013, p. 90-91. ISSN 1677-7042. 2013.

INOMATA, S. O.; FREITAS, C. E. C. A pesca comercial no médio rio Negro: Aspectos econômicos e estrutura operacional. Boletim do Instituto de Pesca, São Paulo, v. 41, p. 79- 87, 2015.

ISAAC, V. J.; ALMEIDA M. C. de. El consumo de pescado em la Amazonia Brasiliena. COPESCAALC/OP13, ISSN 2224-8536 FAO: ROMA. 2011. p. 54

ISAAC, V. J. ; RUFFINO, M. L.; MELLO, P. Considerações sobre o método de amostragem para a coleta de dados sobre a captura e esforço pesqueiro no médio amazonas. In: IBAMA, Coleção meio ambiente. Série estudos pesca. IBAMA: Brasília, n. 22, p. 175-199, 2000.

ISAAC, V. J.; ALMEIDA, M. C.; GIARRIZZO, T.; DEUS, C. P.; VALE, R.; KLEIN, G.; BEGOSSI, A. Food consumption as an indicator of the conservation of natural resources in riverine communities of the Brazilian Amazon. Anais da Academia Brasileira de Ciências, v. 87, n. 4, p. 2229-2242, 2015.

ISAAC, V. J.; BARTHEM, R. B. Os recursos pesqueiros da Amazônia brasileira. Boletim Museu Paraense Emilio Goeldi, Antropologia, Belém, v. 11, p. 295-339, 1995.

ISAAC, V. J.; RUFFINO, M. L. Informe estatístico do desembarque pesqueiro na cidade de Santarém, PA: 1992-1993. In: FISCHER, C. F. (Ed.). Recursos pesqueiros do Médio Amazonas: biologia e estatística pesqueira. Brasília: IBAMA/GTZ/GOPA, 2000. p. 225-280.

JUNK, W. J.; BAYLEY, P. B.; SPARKS, R. E. The flood pulse concept in riverfloodplain systems. In: DODGE, D. P. (Ed.). Proceedings of the of international 
Large River Symposium. Canadian Special Publication of Fisheries and Aquatic Sciences, 1989. p. 110-127.

LIMA, M. A. L.; DORIA, C. R. C.; FREITAS, C. E. C. Pescarias artesanais em comunidades ribeirinhas na Amazônia brasileira: perfil socioeconômico, conflitos e cenário da atividade. Ambiente e Sociedade, [online]. v. 2, p. 73-90, 2012.

MPA - Ministério da Pesca e Aquicultura. Boletim estatístico da pesca e aquicultura; Brasília, Brasil, p. 128. 2010.

MURRIETA, R. S. S.; BAKRI, M. S.; ADAMS, C.; OLIVEIRA, P. S. de S.; STRUMPF, R. Food intake and ecology of riverine populations in two Amazonian ecosystems: a comparative analysis. Revista de Nutrição, v. 21, p. 123-133, 2008.

NEVES, J. G. Ribeirinhos, desenvolvimento e a sustentabilidade possível. 2005. Disponível em: http://www.partes.com.br/socioambiental/ribeirinhos.asp. p.110. ISSN 1678-8419. Acesso em: 18 abr. 2013.

QUEIROZ, L. J.; TORRENTE-VILARA, G.; ZUANON, J.; OHARA, W.; PIRES, T.; DORIA, C. R. C. (Org.). Peixes do rio Madeira. 1. ed. São Paulo: Dialeto, 2013. 1170p.

R CORE TEAM. R: A language and environment for statistical computing. 2014 R Foundation for Statistical Computing, Viena, Áustria. Disponível em: < http:// www.R-project.org >. Acesso em:

RÊGO, J. F. Amazônia: do extrativismo ao neoextrativismo. Ciência Hoje, Rio de Janeiro, v. 25, p. 62-65, 1999.

SANTOS, G. M.; FERREIRA, E. J. G Peixes da Bacia Amazônica. In: LOWEMcCONNELL, R. H. Estudos ecológicos de comunidades de peixes tropicais. Universidade de São Paulo: São Paulo, 1999. p. 345-373.

SANTOS, G. M.; FERREIRA, E. J. G.; ZUANON, J. A. S. Ecologia de peixes da Amazônia. In: VAL, A. L.; FIGLIUOLO, R.; FELDBERG, E. (Ed.). Bases científicas para estratégias de preservação e desenvolvimento da Amazônia: fatos e perspectivas. Manaus: INPA, 1991. p. 263- 280.

SANTOS, G. M. Composição do pescado e situação da pesca no estado de Rondônia. Acta Amazonica, Manaus, 16/17, p. 43-84, 1986/87.

SILVIA, A. L.; BEGOSSI, A. Biodiversity, food consumption and ecological niche dimension: a study case of the riverine populations from the Rio Negro, Amazonia, Brazil. Environment Development and Sustainability , v. 11. p. 489$507,2009$. 
SMITH, N. H. 1979. A pesca no Rio Amazonas. 1. ed. Manaus/ Brasília: INPA/ CNPq, 154p.

SOUZA FILHO, P.W.M., QUADROS, M.L.E.S., SCANDOLARA, J.E., Silva, E.P. e Reis, M.R. Compartimentação morfoestrutural e neotectônica do sistema fluvial Guaporé- Mamoré - Alto Madeira, Rondônia-Brasil. Revista Brasileira de Geociências v.29, p.469-476. 1999.

STATSOFT, INC. Statistica (data analysis software system). Version 7.1. 2005. Disponivel em: <www.statsoft.com>. Acesso em: 10 dez. 2012.

TORRENTE-VILARA, G.; ZUANON, J.; LEPRIEUR, F.; OBERDORFF' T. E.; TEDESCO, P. Effects of natural rapids and waterfalls on fish assemblage structure in the Madeira River (Amazon Basin). Ecology of Freshwater Fish, v. 20, p. 588-597, 2011. 


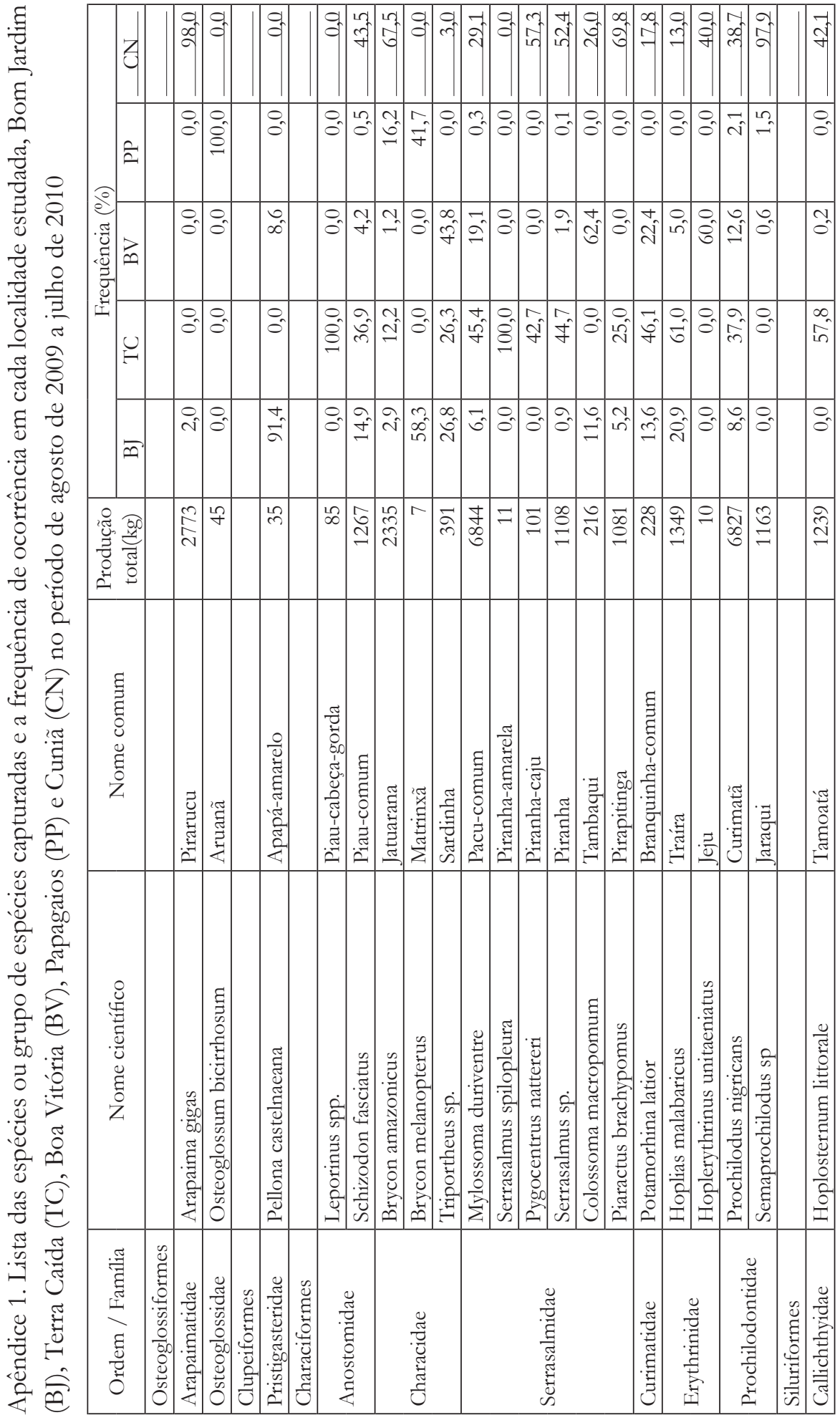




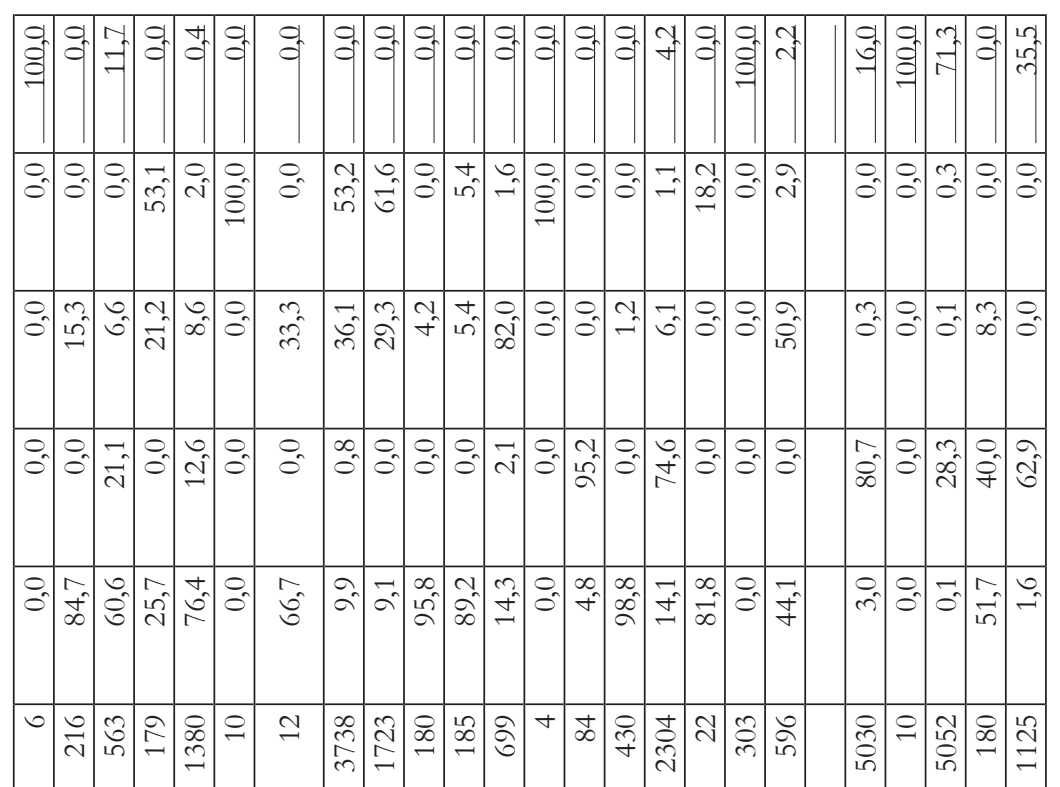

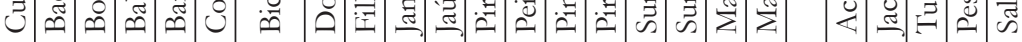

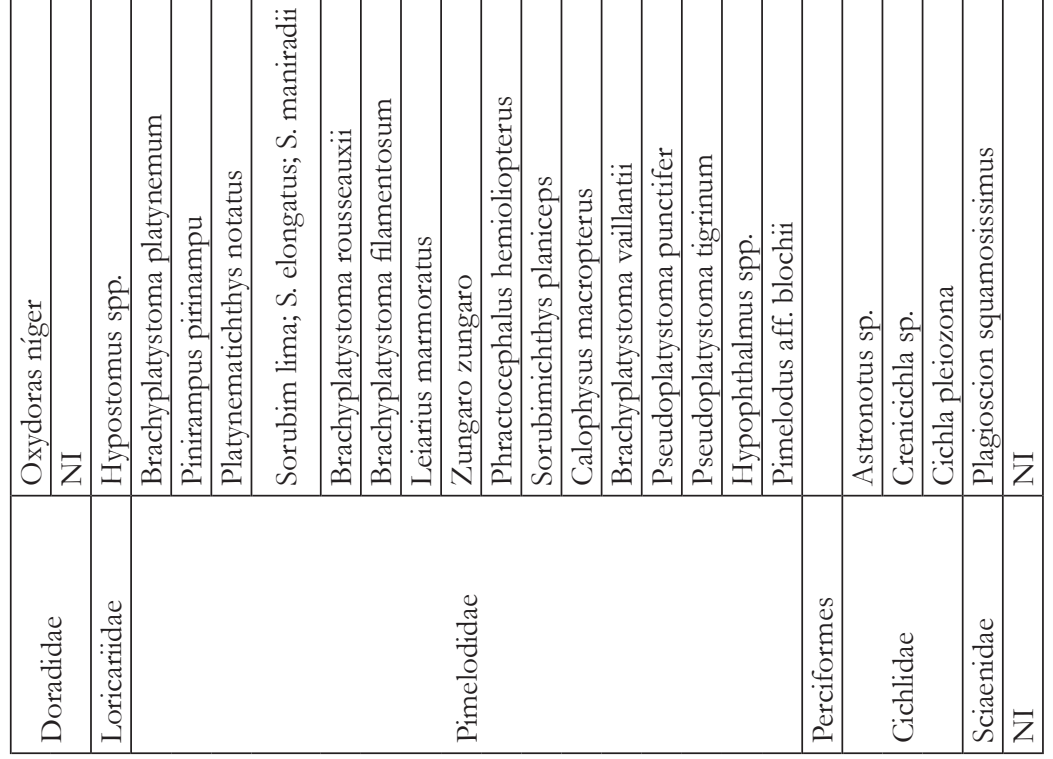


